\title{
Study on Multimodal Video Driver Applying in Flipping Classroom in College English Audio-visual-oral Mode
}

\author{
Author: YAO Fanmei \\ Foreign Languages School, Wuhan Textile University \\ Wuhan, China \\ E-mail:yfm915@126.com
}

\begin{abstract}
This article explores Higher Education institutions to undergo flipped classrooms which are transformation, shifting the educational focus from the traditional and passive lecturebased teaching to an active engagement of students. Apply multimodal video driving mode to improve college students English ability in audio-visual-oral. Discuss how the task designed, task-oriented cooperative learning pattern and evaluation mechanism of teachers to make students get more recognition, achieve the best learning effect. Draw the conclusion: it is obviously that not only the students' audiovisual-oral ability has great improvement, but also their autonomous learning ability, subject consciousness, language comprehensive ability and cultural quality have played a considerable role. It plays a positive role in guiding the practice in the new reform of English teaching. It fully demonstrates that the topic is credible in theory, and it is also possible in practice.
\end{abstract}

Key words-multimodal video driver; flipped classrooms; taskbased teaching methods, student-centered learning

$$
\text { I. }
$$

\section{INTRODUCTION}

There is an increasing research for Higher Education institutions to undergo flipped classrooms which are transformation, shifting the educational focus from the traditional and passive lecture-based teaching to an active engagement of students with each other and with faculty. The education is seen as needing to adapt in ways that meet the needs of our time. Not only are homework and lecture sessions flipped, students create, or "construct" knowledge outside of class and present to others through group learning activities. The creativity involved in the students learning while teaching is enhanced through the use of multimodal video driver (e.g. movie appreciation, movie review and movie maker etc). This article moves beyond exchanging classroom lectures and traditional homework for student watched lectures or videos outside the classroom to free up time for interaction inside the classroom. This approach also works within interactive small-groups and teaching both take place asynchronously on-line. The teacher introduces a topic or assignment and then steps aside to allow the students to become the teacher. This study finds reversing the role of the student from passive observer to an active participant improves the overall learning. It is a myth that synchronous group work is more meaningful. Why do we choose multimodal video driving to improve the students' ability of audio-visual-oral?

Because human civilization and cognition are the result from reading image era. Research shows about $85 \%$ of the people are born with preference for visual learners. With the development of network technology, the video sites with a lot of free movie resources provide vivid corpora for language learners, which containing text, images, sound, and other visual effects are more typically video discourse mode and play an irreplaceable role in people's life. Film, speech contest video etc. as corpus are becoming mainstream of university campus culture and very popular with the students. Students spend a lot of time in all kinds of good and bad intermingled films and television videos, but miss the improvement of humanistic quality and English level which lead to the serious situation of "time consuming with low efficiency" and "cultural aphasia" "dumb English" " butter-tonsiled with empty in mind" and "absence of analytical thinking". It is an urgent thing how to guide the students scientifically to become modern network video beneficiaries rather than the victim. Traditional single-mode teaching method cannot effectively improve the students' learning ability of audio, visual, speaking. To cultivate the students' learning ability, independent thinking and need the demands for the development of connotation have become one of the most important content of the National Medium and Long-term Education Reform and Development Plan Outline (2010-2020). From study on multimodal video driver flipping classroom, we explore the learning ability, strategy and the training method which provide reference for language teaching practice and education policy in college English audio-visual-oral. The objectives of this study are:

\section{A. To examine how the multimodal video driving flipping classroom project helps English audio-visual-oral ability and comprehensive quality improved greatly;}

B. To explore how the task designed, cooperation pattern and evaluation mechanism of teachers to make students get more recognition, achieve the best learning effect.

II.

\section{LITERATURE REVIEW}

At home and abroad multimodal research focuses on using language theory to analyze the static corpus. Mr. Kress \& van Leeuwen(1996) "Reading Images: The Grammar of Visual Design”[1], which is established visual grammar image analysis framework theory, and their study multimodal classroom teaching. On multimodal research methods, Baldry and Thibault's (2006) [2] "Multimodal Transcription and Text Analysis", makes up for the multimodal discourse analysis in the field blank. in which the multimodal discourse is introduced the transcription and 
analysis method in detail, such as teaching materials, web pages, movies, cartoons, etc. Thibault and Baldry apply Halliday's theory of social semiotics, which provides visual discourse analysis framework created by "reproduction", "interactive" and " compositional meaning" as the core of the visual image analysis grammar theoretical framework. Domestic professors Gu Yueguo (2006)[3], Hu Zhuanglin(2007)[4], Wei Qinghong (2009)[5], etc. use the systematic functional language theory to analyze multimodal discourse. They think discourse analysis should not be confined to the language itself, should be paid attention to the image, sound, color and other forms. And flipping classroom practiced first by Salman Khan in 2006 is popular in the 21st century in the United States reverses traditional knowledge internalization after class into in class. Students complete the task in the classroom with the help of teacher and classmates, which pour into a new teaching form for this study. Abroad research focused on the design and implementation of teaching strategy, concept, connotation and the comparison with the traditional classroom, etc. Domestic research has just started, the main is still in the theoretical exploration, pattern design, the construction phase, and the research lags behind the development of times, but this issue applying audio-visual teaching method is much less. This topic through empirical research, explore integrating practicability, informative and interesting, practical audio-visual teaching mode.

\section{III.}

METHOD

\section{A. The specific research object and content}

This study bases on our school courses of "English audio-visual-oral" , "English film and television audiovisual-oral", "Academic English audio-visual-oral", " Media English audio-visual-oral" curriculum as the main body, the object of study for a random sample of non-English major undergraduate in our school. Class A, 70 students is as the experimental group and class B, 69 students as control group. Adopt the proposed investigation of hybrid method. The research content goes through the comparative analysis of multimodal video driver flipping classroom teaching mode and the effect of traditional teaching mode, discusses the issue of application of cooperative learning strategy in English audio-visual course, puts forward to "task" to construct the classroom by flipping classroom form. To identify the strategy is to improve students' listening skills and language communicative ability, to foster the spirit of cooperation, to realize the effective method of the coordinated development of individuals and groups. To seek a kind of most effective audio-visual-oral teaching mode. Its teaching effect is measured mainly by their impact on the students' language output level.

\section{B. Experimental basic procedure is as follows:}

(1) Before the test: students' English output level for the experimental group and control group

(2) Teaching practice: experimental group - multimodal video driver flipping classroom learning strategy group, according to Willis (1996)[6] the task teaching mode of three stages:

1) Pre-task phase: including introduction topics and preparation for the task which highlights teacher's "dominant" function; With the help of a network teachers establish the QQ learning or cloud computer network platform. They provide students with useful input, activate the relevant knowledge and appreciation of movie language skills to help students in a networked environment understand the task of theme, content and goals, arousing the students interest and enthusiasm, guide students to prepare the task. According to Ying-ling Deng's homogeneity between groups, heterogeneity in group to establish cooperation team by listening and oral test dividing groups before the course, the teacher based on the students' gender, test scores, willingness and ability of organization and communication, guides the students to build friends circle, about 4 to 5 people in each group. Distinguish each group's language ability and comprehensive ability into diamond structure, strong and weak type around $20 \%$ students, one by a self or group recommendation way to become a leader, who takes the role of organization, stimulation and contact. This phase includes: rendering tasks, collection of videos, role assignments.

2) Task-cycle (the implementation phase of the task), including the participant's activities, plans and reports. Highlight students' "principal part” at this stage. In flipping classroom students are driven to watch movies and videos by task-based before class and to organize activities in class, which can complete the learning process of knowledge internalization and transfer information which follow the learner's cognitive rules. The students design and perform the task in which way they like. In the light of the features of task-based learning strategies, students implement the task content. The type of cooperative learning task according to the difficulty index can be divided into mandatory task, speculative task, competitive tasks, communicative task, investigative task, debate and design task. In classroom teacher asks questions about the video content. The entire process leads with corpus-based theme, taking the interaction between teachers and students, students interaction and human-computer interaction way, learning and using multimodality to present personal reviews, to achieve from the text to image, from connotation of voice to really understanding the language usage scenarios, the final result is that the students can output correctly. This model constructs knowledge, eventually, to maximize students' creativity, realize their main body status. Learning is most effective when students are creating. The learning is centered on the student. The teacher taps into the students' previous knowledge to facilitate new learning. When there is relevance to their lives and their interests, students can actively engage in the creating, understanding, and connecting with the attainment of knowledge (McCombs \& Whisler, 1997)[7].This phase includes: plot discussion, compile micro film, language skill training. 
3) Post-task (evaluation phase):construction "teacherstudent" "students-students" interactive mode, to encourage them to participate in the discussion and analysis actively. Students assess each other from grasping film language feature to listening skill, from language application to communication effectiveness, from coordination to participation, from progress to cooperation spirit and comprehensive ability. Students make self and group evaluation through comment so that they can learn from each other and improve together. Teacher's comments combine with the characteristics of western culture, language skills and the integrated ability of language use. Teachers may use the combination approaches, quantitative evaluation and qualitative description, from the knowledge of the language to culture, skills and other aspects, assess the performance of students' task. Self-evaluation, mutual evaluation in students account for $25 \%, 25 \%$ and teachers in comprehensive scores cover 50\%.The evaluation mechanism forms include process evaluation and result evaluation of three-dimensional structure which realize the stability and fairness well, in conformity with the English audio-visual teaching assessment.

Control group — - traditional teaching method:

1) Students preview the text before class, recite the corresponding words.

2) The textbook is "New Horizon College English Audiovisual Course", according to traditional methods to train students in class based on close to real communicative situations of single mode or dual modal mechanical listening exercises, teachers analyze textbook, students answer the problems related text. To put in classroom context, in a teacher-centered environment the instructor is the sole disseminator of knowledge.

(3) Post-test

After two semesters teaching, we test two groups about language ability from depth and width, we employ the data in a unified final exam in the university, take listening and speaking each with $20 \%$ as the full mark to measure output of students' foreign language level.

IV.

DATA ANALYSIS AND

\section{DISCUSSION}

The number of the students in Class A, experimental group, is 70; the number of the students in Class B, control group, is 69. The author tested both groups before the experiment just to make sure the groups were really the same, especially in English listening ability. The author took data from the Term Examination paper to test the freshmen's listening comprehension and oral test as pretest in January 2012. The two total scores are separately $20 \%$. The test showed that these two groups were approximately at the same level of listening and speaking proficiency before the research, as the following Table 1 shows. After two semesters we adopt new teaching method, the result is shown as the following Table 2 :
Table 1 Pretest Data Analysis of Two Groups in the First Term

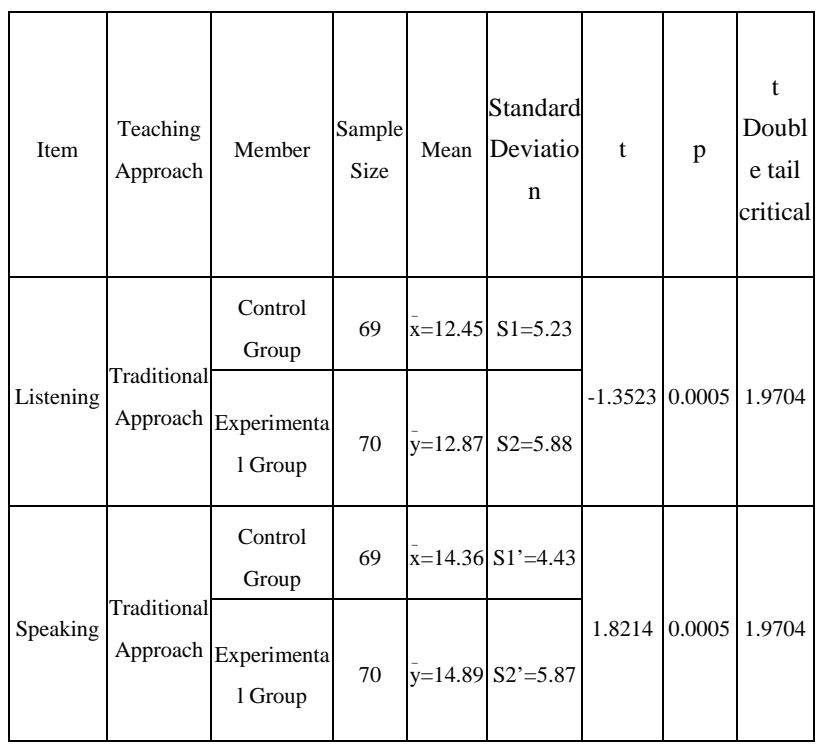

Table 2Post-test Data Analysis of Two Groups in the Final Term

Table 1 shows: Under the condition of 95\% confidence

\begin{tabular}{|c|c|c|c|c|c|c|c|c|}
\hline Item & $\begin{array}{c}\text { Teaching } \\
\text { Approac } \\
\text { h }\end{array}$ & Member & $\begin{array}{c}\text { SampleS } \\
\text { ize }\end{array}$ & Mean & $\begin{array}{l}\text { Standard } \\
\text { Deviation }\end{array}$ & $\mathrm{t}$ & $\mathrm{p}$ & $\begin{array}{c}\text { t Double } \\
\text { tail } \\
\text { critical }\end{array}$ \\
\hline \multirow{2}{*}{ Listening } & $\begin{array}{c}\text { Tradition } \\
\text { al } \\
\text { Approac } \\
\text { h }\end{array}$ & $\begin{array}{l}\text { Control } \\
\text { Group }\end{array}$ & 69 & $\bar{x}=12.56$ & $\mathrm{~S} 1=4.35$ & \multirow{2}{*}{2.7345} & \multirow{2}{*}{0.0005} & \multirow{2}{*}{1.9712} \\
\hline & $\begin{array}{c}\text { Using } \\
\text { Videos }\end{array}$ & $\begin{array}{c}\text { Experimen } \\
\text { tal Group }\end{array}$ & 70 & $\bar{y}=16.74$ & $\mathrm{~S} 2=2.78$ & & & \\
\hline \multirow{2}{*}{ Speaking } & $\begin{array}{c}\text { Tradition } \\
\text { al } \\
\text { Approac } \\
\text { h }\end{array}$ & $\begin{array}{l}\text { Control } \\
\text { Group }\end{array}$ & 69 & $\bar{x}=14.67$ & $\mathrm{~S} 1^{\prime}=5.24$ & \multirow{2}{*}{3.4501} & \multirow{2}{*}{0.0005} & \multirow{2}{*}{1.9712} \\
\hline & $\begin{array}{c}\text { Using } \\
\text { Videos }\end{array}$ & $\begin{array}{c}\text { Experimen } \\
\text { tal Group }\end{array}$ & 70 & $\bar{y}=17.98$ & $\mathrm{~S} 2^{\prime}=3.12$ & & & \\
\hline
\end{tabular}

level for double check the difference between the sample mean, establish a hypothesis $\mathrm{H} 0$ : experimental group and control group students have no significant difference in listening and speaking, namely the M1-M2 $=0,|\mathrm{t}|<1.9704$, the fall in the acceptable region, therefore assuming $\mathrm{HO}$, namely at the beginning of the experiment, the level of experimental group and control group in listening and speaking is no significant differences. Let's read table 2: | t $\mid>1.9712$, the fall in the rejection region, thus assuming H0, namely after the experiment, the experimental group and control group there are significant differences on students in listening and speaking. The multimodal video driving 
flipping classroom project helps English audio-visual ability and comprehensive quality improved greatly

In order to fully understand the students' cognition of task-oriented cooperative learning and its influence on English audio-visual-oral teaching in flipping classroom, the researchers design questionnaire according to Likert five scale way, integrate most of the students' idea that the videotext by task-oriented cooperative learning strategy in flipping classroom can improve the learners' interest and motivation (78.5\%), language skills (64.2\%), and the ability to learn (70.3\%), strengthening students' self-confidence (75.6\%), cultivating a strong will (76.9\%) and self emotion regulation (56.8\%), the biggest advantage is embodied in the social communication ability (86.7\%), the cultivation of the spirit of cooperation (94.3\%). From the above data, we can clearly tell the multimodal video driving in flipping classroom project in cooperative mode reduces the anxiety of the students in the process of learning, enhances the students' self-confidence, eliminates the learners' psychological barriers effectively and achieves the purpose of improving the ability of audio-visual-oral.

The second question for the research is the task designed, cooperation pattern and evaluation mechanism of teachers to make students get more recognition, achieve the best learning effect. According to students' different recognition types, we design different task that the recognition of the mandatory task and speculative task is about $14.3 \%$, competitive tasks19.7\%, communicative tasks and investigative task about $22.3 \%$, debate tasks $27 \%$ and design task16.7\%. The research shows students do not escape competition in task-based cooperative learning. They like challenging when facing higher request for innovation ability and comprehensive quality. Students have higher recognition in the evaluation mechanism of cooperative learning. Studies show that evaluation mechanism avoids the traditional disadvantages of only teachers' evaluation, reduces the students' test anxiety and nervousness, conforms to the regulation of language teaching, perfects the evaluation system.

Why have group/team assignments?

To demonstrate that teams are able to produce work that is better than an individual student's work

To allow students to practice and develop the interpersonal and rational skills that are important for success in any discipline

To demonstrate the strengths and weaknesses of asynchronous communication and coordination in the 21st century world

Require students to extend their understanding of the topic, to explore it further or deeper than the videos, or to think critically about the topic

Require students to make connections: How does the video or movie integrate with practice, with personal experience or with other assigned readings?

After completion of the assignments using the video discourses, the students felt "great," "confident," stated it was "more exciting than before," "an influential method to teach," "gave a sense of self-esteem and confidence." Students have an affinity for social media and technology.
They enjoy the creative experience of making their own brief video lectures.

Teachers are able to move well beyond flipping the classroom by allowing students the freedom to "learn-bymaking”. Flip the classroom creating an opportunity for the student to teach, and thereby to make themselves think more deeply while creating engaging, inspiring, and provocative videos. The class creation of knowledge, critical thinking. By taking ownership of their learning, students find things out for themselves rather than passively accept what they hear in a lecture.

\section{V.CONCLUSION}

To conclude, we feel that not only flipping the classroom enabling students to "learn-by-making", but also to learn by teaching others. There is benefit in activities which foster the development of audio-visual-oral skills for young people through activities that they typically enjoy, are motivated by, and, in some cases, for which they have an aptitude. Additionally, we feel that there is promise in developing environments which explicitly link young people's existing skills, in this case, an ability to make movie review in authentic language, skills to be developed, in this case, programming and computational skills more broadly. It fully demonstrates that the topic is credible in theory, and it is also possible in practice. Further research will allow us to better understand and specify the nature of these links and how to provide optimum support in the environments we design.

\section{ACKNOWLEDGMENT}

First we would thank the research supported by Hubei Provincial Higher Education Institutions Teaching Research Project in 2014, No. 2014449, Title: Study and Practice on Multimodal Video Driver Applying in Flipping Classroom in College English Audio-visual-oral Mode. we are also very grateful to the policy of our university. Thanks to the teachers and pupils who so willingly took part in our participatory design and evaluation studies.

\section{REFERENCES}

[1] Kress, G.\& van Leeuwen, T. "Reading Images: The Grammar of Visual Design” [M]. Burwood:Brown Prior Anderson,1996 pp133

[2] Baldry, A. P. \& P. J. Thibault. "Multimodal Transcription and Text Analysis” [M]. London: Equinox, 2006.pp15-36

[3] Gu Yueguo. Multimodal text analysis: A corpus linguistic approach to situated discourse[J]. Text and Talk, 2006a, 26-2:127-167

[4] Hu Zhuanglin. "Multimodal Social Semiotics Research” [J]. Language Teaching and Research, 2007 (1) ,pp1-10

[5] Wei Qinghong. Studies on Multimodality and Multimodal Discourse in Visual Surroundings [M] 2009

[6] Willis, J. A "Framework for Task-based Learning” [M]. London: Longman, 1996. pp78

[7] McCombs, B.L., \& Whisler, J.S. The learner-centered classroom and school: strategies for increasing student motivation and achievement[M]. San Francisco: Jossey-Bass1997 